\title{
Matching radiative transfer models and radiosonde data from the EPS/Metop Sodankylä campaign to IASI measurements
}

\author{
X. Calbet $^{1}$, R. Kivi ${ }^{2}$, S. Tjemkes ${ }^{1}$, F. Montagner ${ }^{1}$, and R. Stuhlmann ${ }^{1}$ \\ ${ }^{1}$ EUMETSAT, Eumetsat-Allee 1, 64295 Darmstadt, Germany \\ ${ }^{2}$ Finnish Meteorological Institute, Arctic Research Centre, Tähteläntie 62, 99600 Sodankylä, Finland
}

Received: 23 June 2010 - Published in Atmos. Meas. Tech. Discuss.: 20 October 2010

Revised: 11 May 2011 - Accepted: 7 June 2011 - Published: 23 June 2011

\begin{abstract}
Radiances observed from IASI are compared to calculated ones. Calculated radiances are obtained using several radiative transfer models (OSS, LBLRTM v11.3 and v11.6) on best estimates of the atmospheric state vectors. The atmospheric state vectors are derived from cryogenic frost point hygrometer and humidity dry bias corrected RS92 measurements flown on sondes launched $1 \mathrm{~h}$ and $5 \mathrm{~min}$ before IASI overpass time. The temperature and humidity best estimate profiles are obtained by interpolating or extrapolating these measurements to IASI overpass time. The IASI observed and calculated radiances match to within one sigma IASI instrument noise in the spectral region where water vapour is a strong absorber (wavenumber, $v$, in the range of $1500 \leq v \leq 1570$ and $\left.1615 \leq v \leq 1800 \mathrm{~cm}^{-1}\right)$.
\end{abstract}

\section{Introduction}

The main purpose of the space-based remote-sensing instruments, known as hyperspectral infrared sounders, is to derive high vertical resolution atmospheric parameters from high spectral resolution measurements. This technique is usually known as "retrieval". The spectral region where hyperspectral infrared sounders usually work is from 600 to $2800 \mathrm{~cm}^{-1}$ and its spectral resolution is typically about $0.5 \mathrm{~cm}^{-1}$. The typical noise per channel of these instruments is roughly in the range from 0.1 to $0.8 \mathrm{~K}$ as noise equivalent delta temperature at $280 \mathrm{~K}$. Retrievals obtained with measurements made with this type of instrument achieve an accuracy of $1 \mathrm{~K}$ in

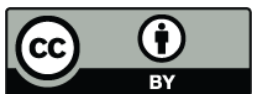

Correspondence to: $\mathrm{X}$. Calbet

(xavier.calbet@eumetsat.int)
$1 \mathrm{~km}$ layers for temperature profiles and between 10 to $20 \%$ relative humidity in $2 \mathrm{~km}$ thick layers for moisture profiles in the troposphere (Smith et al., 2001). Throughout this paper we will use measurements from the IASI hyperspectral infrared sounder (see Sect. 2).

Retrieval techniques usually rely on an atmospheric Radiative Transfer Model (RTM). These models try to numerically reproduce the radiation at the top of the atmosphere calculated from a given atmospheric state and surface properties. Calculated radiances are then matched to the observed ones during the retrieval process. This is generally done in two different ways, statistically or with optimal estimation. Statistical methods generate a training dataset by calculating, from a representative sample of atmospheric states and RTMs, radiances at the top of the atmosphere. This dataset is used to fit a linear regression (Huang and Antonelli, 2001; Zhou et al., 2002) or other nonlinear methods like artificial neural networks (Blackwell, 2005), which are later used in an inverse way to generate the retrievals. Optimal estimation $(\mathrm{OE})$ performs the retrievals by minimizing the difference between the calculated and the observed radiances and a regularisation term by using a minimizing iterative numerical method (Rodgers, 2000).

It is usually the case that RTMs cannot be used in practice as is in the retrieval schemes. They usually need to be adjusted to real world measurements. This is normally done by bias correcting the radiances and estimating the global measurement error by comparing the observed and calculated radiances for a given set of well-defined atmospheric states and surface properties (e.g., Calbet and Schlüssel, 2006). Thus, the characterisation of the RTM with calibration measurements is a necessary and critical step before performing proper retrievals. 
Another possible application of the comparison of hyperspectral measurements and calculated radiances using known atmospheric states and an RTM is to improve the latter by adjusting its parameters to the said observations. In order to do this, we need to be absolutely certain that we have a very precise atmospheric state vector and surface properties or we need to have a sufficient number of observations to statistically reduce the noise in them (e.g., Strow et al., 2006).

A completely different approach is to directly compare retrieved atmospheric profiles with the radiosonde measurements. This methodology provides a better validation of the retrievals themselves, but involves an added step, the retrieval algorithm, which complicates the subject further. It is then more difficult to identify what is the source of any possible discrepancies than with the direct comparison of radiances. To adequately perform this type of validation different techniques have been applied like correcting the sonde measurements with "microwave scaling" (Tobin et al., 2006) or addressing the errors involved in all measurements (Pougatchev et al., 2009).

In this paper, the radiance comparison approach will be adopted by comparing IASI measurements with calculated radiances obtained from radiosonde measurements and RTMs. We will show how to correct the atmospheric states derived from the Atmospheric Sounding Campaign of the EUMETSAT Polar System (EPS) in Sodankylä to accurately describe the atmosphere. We later fit and characterize two radiative transfer models (LBLRTM and OSS, see Sect. 4) in the 1500 to $1800 \mathrm{~cm}^{-1}$ spectral region using space borne hyperspectral IASI data. This spectral region is where water vapour has its strongest absorption bands. The atmospheric layers that most greatly contribute to the top of the atmosphere radiances in this spectral region are located in the mid to high troposphere and lower stratosphere. This fact makes these wavenumbers most insensitive to low level clouds and surface properties like surface emissivity and skin temperature. Because of this, the problem is greatly simplified by not having to provide a precise surface emissivity and by being able to use observations with the presence of low-level clouds.

In Sect. 2 the IASI instrument is briefly introduced. Section 3 explains the Sodankylä ground based campaign and its main instruments. The RTMs are introduced in Sect. 4. Section 5 explains how the sonde measurements are bias corrected and interpolated to reproduce the observed radiances using the RTMs. In Sect. 6 it is discussed how these measurements could be used to estimate the bias corrections and measurement error covariance matrix to be used in the retrieval techniques. Finally, conclusions are detailed in Sect. 7.

\section{IASI instrument}

IASI (Infrared Atmospheric Sounding Interferometer; Chalon et al., 2001; Blumstein et al., 2004) is a hyperspec- tral resolution infrared sounder onboard the polar orbiting series of Metop satellites that form the EUMETSAT Polar System (EPS). Metop-A, the first of three satellites of the series was launched successfully on 19 October 2006, from the Baikonur Cosmodrome in Kazakhstan. IASI is a Michelson interferometer measuring between 3.62 and 15.5 microns with a spectral resolution of $0.5 \mathrm{~cm}^{-1}$ after apodisation. Data samples are taken at intervals of $25 \mathrm{~km}$ along and across track, each sample having a maximum diameter of about $12 \mathrm{~km}$ at nadir.

In the comparison exercise, the closest field of view to the Sodankylä observatory was used. The observatory location is usually enclosed within the selected field of view.

\section{EPS/Metop Sodankylä campaign and instruments}

The Atmospheric Sounding Campaign of the EUMETSAT Polar System (EPS) in Sodankylä, northern Finland (location: $67.368^{\circ} \mathrm{N}, 26.633^{\circ} \mathrm{E}, 179 \mathrm{~m}$ a.s.1.) took place during the time period 4 June-5 September 2007. During the campaign, a total of 360 RS92 radiosondes, 40 ECC ozonesondes and 7 cryogenic frost-point hygrometers (CFH) were flown. The 360 radiosondes corresponded to Metop-A overpasses on each calendar day, assuming 2 soundings per each overpass during three months of operation. Ozonesondes were launched 3 times per week, CFH sondes in average two times per month. Each CFH sonde payload included also an ozonesonde, two RS92 radiosondes for comparison purposes and one RS80 radiosonde attached to the CFH instrument, primarily to provide data transmission. The measurements were made with the purpose to provide validation data for temperature, humidity and ozone parameters at given levels for the EPS products at the location of the campaign site. It is interesting to note that these sondes were launched specifically for calibration and validation of EPS/Metop data and its measurements have not been assimilated into any numerical weather prediction model, and particularly they have not been involved in any ECMWF analysis.

During each selected Metop overpass, the first radiosonde launch took place $1 \mathrm{~h}$ and the second radiosonde launch was $5 \mathrm{~min}$ before the satellite overpass time. We performed, in total, four launches each day, the first two during the morning overpass and the second two during the evening overpass. In addition, regular radiosondes were launched at 23:30 and 11:30 UT each day. The ozonesondes and the CFH sondes, together with RS92 sondes, were launched during the morning overpass with the first balloon, which occurred $1 \mathrm{~h}$ before the satellite overpass time. During the balloon launches, continuous measurements of the temperature and water vapour profiles were obtained by a ground-based microwave radiometer and cloud base was measured by a ceilometer. In this paper, only the CFH and RS92 balloon-borne measurements have been used. It is important to note that all balloon 
flight measurements used in this paper were made during daytime, which, as we will see later, produces a large dry bias in the RS92 sondes.

\subsection{Cryogenic frost-point hygrometer (CFH)}

In Sodankylä, first flights of the $\mathrm{CFH}$ instrument were made in February 2004 (Suortti et al., 2008). Also several CFH comparison flights with the Fluorescent Lyman-alpha Stratospheric Hygrometer for Balloons (FLASH-B) were performed since 2005 confirming a good agreement between them. In summer 2007, during the EPS campaign an updated version of the $\mathrm{CFH}$ instrument was flown in Sodankylä.

The CFH instrument was used as a reference for humidity profile measurements during our EPS campaign. The instrument measures the temperature of a mirror, which maintains a small and constant layer of frost coverage. The frost layer is kept in equilibrium with water vapour in the air passing through the sensor. Thus, the ambient frost-point is equal to the mirror temperature. The cryogenic cooling of the frost-point mirror ensures that the frost-point temperatures are achieved even in the coldest and driest layers. Relative humidity and mixing ratio can be calculated based on the frost-point temperature measurement. The design of the instrument is based loosely on the earlier versions of the frostpoint mirror hygrometers by Mastenbrook and Dinger (1960) and Oltmans and Hofmann (1995). Compared to its predecessors, the CFH has a more modern electronic system with a microprocessor control which has led to a simpler operation and improved reliability (Vömel et al., 2007a). Measurement relative uncertainty of the $\mathrm{CFH}$ instrument in the polar region (Sodankylä) ranges between $9 \%$ in the lower stratosphere and about $4 \%$ in the lower troposphere. The uncertainty calculation is based on the estimate of the uncertainty in frost-point temperature measurements. Several factors contribute to the uncertainty estimate leading to a total uncertainty estimate of $0.5 \mathrm{~K}$ in frost-point measurement, which can be considered as the upper limit of the uncertainty estimate. For later use, these figures are converted into errors in absolute relative humidity, $\Delta \mathrm{RH}$, which are between 0.5 and $5 \%$ in the troposphere and between 0.5 and $0.02 \%$ in the stratosphere.

\subsection{RS92 radiosondes}

During the EPS campaign 360 Vaisala RS92 radiosondes were flown. RS92 radiosondes have a contrasted quality as shown in its participation in the WMO radiosonde inter comparison campaign at Mauritius in 2005 (Nash et al., 2006) and in a number of other field campaigns (Suortti et al., 2008; Vömel et al., 2007b,c; Miloshevich et al., 2009). The RS92 sonde has been manufactured since 2004 and the changes to the sensor have been documented by Vaisala (2010).

The temperature measurements of these sondes are made by a capacitive wire type of sensor which has a response time better than $1 \mathrm{~s}$ below $100 \mathrm{hPa}$. Temperature accuracy is $\pm 0.2^{\circ} \mathrm{C}$ at the 2 -sigma level throughout the troposphere for nighttime measurements (Paukkunen et al., 2001).

The RS92 humidity sensor is a thin film capacitor that directly measures relative humidity. It consists of two sensors, which are alternately measuring and being heated, thus, eliminating coating of the sensor by ice or liquid inside clouds. Miloshevich et al. (2006) tested a number of operational radiosondes. They found that RS92 humidity was the most accurate among the tested sondes. They suggested corrections to the standard humidity product, after which the RS92 mean accuracy relative to the reference instrument was found to be better than $1 \%$ in the lower troposphere, $<2 \%$ in the middle troposphere and $<3 \%$ in the upper troposphere. These relative errors translate into absolute errors in relative humidity, $\triangle \mathrm{RH}$, between 0.2 and $3 \%$.

Although this accuracy seems to be within bounds for the purposes of the present study, unfortunately the previous versions of the RS92 instruments, which were not used in this campaign, suffer from a very large radiation dry bias (Vömel et al., 2007b) when used during daytime which can range from 9 to $50 \%$ in absolute terms of relative humidity $(\Delta \mathrm{RH})$. One of the important improvements to the latest version is the new coating of humidity sensor contacts in late 2006 Vaisala (2010). These improved sondes (360 sondes altogether) were the ones flown during our campaign in summer 2007. The new coating method was intended to reduce the radiation dry bias found earlier during the RS92 sonde daytime measurements (Vömel et al., 2007b). To confirm this dry bias and to see differences between the two RS92 versions, we made a series of seven RS92/CFH comparison flights during the EPS/Metop campaign in summer 2007. In each payload, we had the new and the old version of the RS92 sonde and the CFH instrument as a reference (Kivi et al., 2009). We found that the new method reduces the radiation dry bias at the altitude of $300 \mathrm{hPa}$ by about $5 \%$ in relative terms of relative humidity, but does not completely remove the daytime dry bias. Therefore, we derived an empirical correction method, which is similar to the Vömel et al. (2007b) method, but it corresponds to the newer sonde type that we used during the EPS campaign (Fig. 1). For the type of RS92 sondes used during the EPS campaign the radiation bias correction can be calculated by (Kivi et al., 2009):

$C_{\mathrm{rad}}(p)=-0.01376 \ln (p)^{2}+0.3018 \ln (p)-0.445$,

where $p$ is pressure in hectopascals. The corrected relative humidity, $\mathrm{RH}_{\text {corr }}$, values can be derived as

$\mathrm{RH}_{\mathrm{corr}}=\mathrm{RH} / C_{\text {rad }}$,

where $\mathrm{RH}$ is the uncorrected relative humidity measured by the RS92 humidity sensor. 

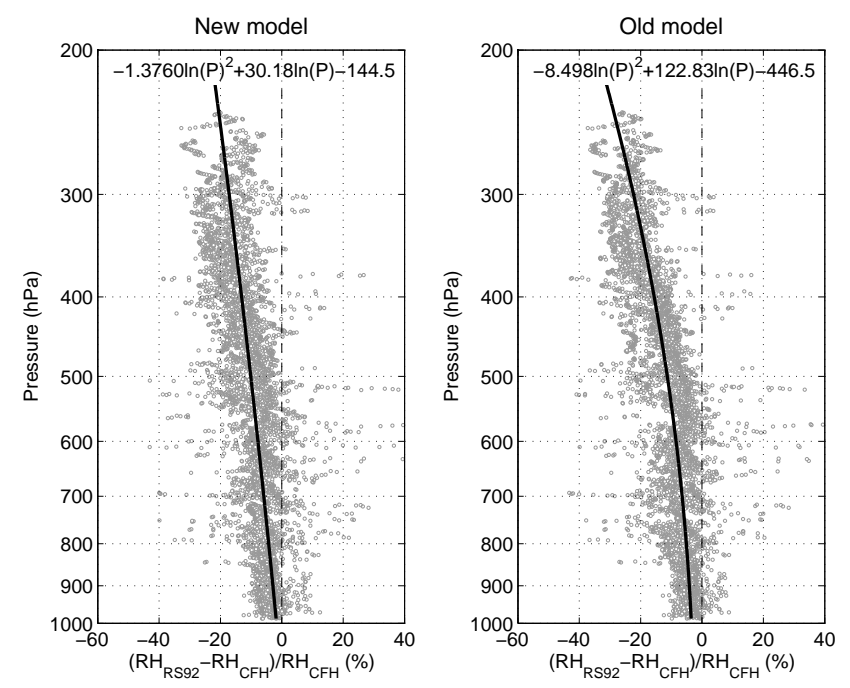

Fig. 1. Relative difference between RS92 and CFH (cryogenic frost point hygrometer) humidity profiles during daytime flights in Sodankylä from June to August 2007. The new model of the RS92 sonde (left) is using aluminized coating of the sensor attachment, which reduces the radiation dry bias compared to the earlier version of the RS92 (right). Both RS92 sonde models and also the CFH sonde were flown in the same balloon payload during the EPS/Metop Sodankylä campaign. The CFH sonde is here used as a reference for both RS92 sonde models.

\section{Radiative transfer models}

We have chosen to use three different versions of the same family of RTMs. Two versions of LBLRTM (11.3 and 11.6), which is a line by line model which is computationally slow, but very precise, and a fast RTM, OSS, not so precise but with a very high speed performance. The reason to also include a fast RTM in this comparison is because in an operational environment, having to produce results in near real time, this is the type of RTM that is preferably used. It is therefore important to also characterize OSS.

The RTMs used are listed here:

- OSS trained with LBLRTM 11.3

- LBLRTM version 11.3

- LBLRTM version 11.6

These three models are described in more detail below.

\subsection{LBLRTM}

Accurate spectra at the top of the atmosphere were generated using the Line By Line Radiative Transfer Model (LBLRTM, Clough et al., 2005). LBLRTM has a long development history and for the current study versions 11.3 and 11.6 were adopted. LBLRTM is a versatile high accurate radiation code which describes the interaction between matter and radiation at a single wavenumber. The accuracy of LBLRTM was documented in several publications (e.g., Tjemkes et al., 2003).

LBLRTM version 11.3 was released in November 2007 and uses the AER spectroscopical database version 2.1, which is based on HITRAN 2004 appended with Niro et al. (2005) line coupling parameters.

LBLRTM version 11.6 was released in June 2009 and uses the AER spectroscopical database version 2.2. LBLRTM v11.6 differs from v11.3 in fixing some issues related to the generation of analytical jacobians. The major difference between v11.3 and v11.6 are improvements in water vapour spectroscopy following Coudert et al. (2008).

\subsection{OSS}

As detailed line-by-line calculations are time consuming, a fast radiative transfer code was used as well to understand how this fast code can capture the radiances at the top of the atmosphere. The particular fast radiative transfer code adopted here was the so-called Optimal Spectral Sampling (OSS) radiative transfer model described by Moncet at al. (2008). The OSS code solves the radiative transfer equation at a single wavenumber similar to the LBLRTM code. Contrary to LBLRTM, the OSS code uses only a small set of discrete wavenumbers. The accuracy of OSS depends on the adopted discrete set. The set of wavenumbers is specific for each space-borne instrument and are derived from an elaborate training process. The training data employs results by LBLRTM for a representative set of atmospheric state. This database was generated using the above described LBLRTM v11.3. The radiative calculations themselves differ from LBLRTM in the assumption of linear dependency of the optical path used in LBLRTM to solve the vertical integration of the source function, which is not implemented in OSS. Another difference is that LBLRTM makes explicit calculations of the temperature and pressure dependency of the absorption coefficients, while OSS interpolates into precalculated lookup tables. Hence there are subtle differences between the two codes, which warrant a comparison as presented in the paper.

\section{Comparison of observed and calculated radiances}

\subsection{Scenes}

The IASI radiances used in this study where measured over Sodankylä and where co-located in time with the CFH sondes from the EPS/Metop campaign. The exact dates and times are shown in Table 1. The AVHRR images corresponding to these scenes were analysed visually to check for clouds. All of the scenes had a higher or smaller degree of underlying low level clouds. Two of the scenes contained high level cirrus and could not be used in the comparison. 
Table 1. Dates and times of IASI observations over Sodankylä with co-located CFH sondes. Comments concerning cloud information have been obtained from visual inspection of AVHRR images.

\begin{tabular}{|c|c|c|c|}
\hline Date & Time (UT) & $\begin{array}{c}\text { Used in } \\
\text { comparison } \\
\text { with RTM }\end{array}$ & Comment \\
\hline 15 Jun 2007 & $09: 20: 42$ & Yes & Low level clouds \\
\hline $13 \mathrm{Jul} 2007$ & 09:41:20 & Yes & Low level clouds \\
\hline $17 \mathrm{Jul} 2007$ & $08: 18: 23$ & Yes & $\begin{array}{l}\text { FOV mostly clear with } \\
\text { some low level clouds }\end{array}$ \\
\hline $20 \mathrm{Jul} 2007$ & $08: 56: 26$ & No & No IASI data in archive \\
\hline $25 \mathrm{Jul} 2007$ & $08: 52: 59$ & Yes & Low level clouds \\
\hline 2 Aug 2007 & $09: 27: 34$ & No & $\begin{array}{l}\text { Low level clouds } \\
\text { plus thin cirrus }\end{array}$ \\
\hline 22 Aug 2007 & $09: 13: 47$ & No & Thick cirrus \\
\hline
\end{tabular}

For one scene there was no IASI data available in the archive. This leaves a final result of four scenes where we can intercompare IASI observations. See Table 1 for particular details.

\subsection{Sonde measurements}

Let us recall here that we will use in this paper one RS92 and one $\mathrm{CFH}$ sonde launched $1 \mathrm{~h}$ before overpass time and an RS92 sonde launched $5 \mathrm{~min}$ before overpass time. To have a sense of how much the sondes have drifted away from the launch location, we plot Fig. 2. In this figure, we show the trajectories of the $\mathrm{CFH}$ sondes of the four selected scenes from Table 1 .

For illustration purposes, the time and vertical scales are plotted in Fig. 3. In this figure, we can see the ascent and descent for one particular day of the CFH sonde launched $1 \mathrm{~h}$ before overpass time and the ascent of the RS92 sonde launched $5 \mathrm{~min}$ before overpass time. The overpass time is plotted as a vertical line. This figure gives an idea of the vertical position of the sondes relative to the overpass time. It also constitutes a picture of the time interpolation that needs to be done to fit the observed radiances to the calculated ones.

Radiosonde measurements for two particular days are shown in Figs. 4 and 5. We can see the profile for the $\mathrm{CFH}$ and RS92 sonde launched $1 \mathrm{~h}$ before overpass time (red and green, respectively), the RS92 sonde launched $5 \mathrm{~min}$ before IASI overpass (black) and the ECMWF analysis profile approximately $3 \mathrm{~h}$ after (blue) and $3 \mathrm{~h}$ before satellite overpass in blue (in grey). These figures show several interesting features of the sonde measurements:

- Temperature profiles from all sondes and ECMWF analyses tend to agree pretty well between each other, except in the layers close to the surface, which are not relevant in this paper.
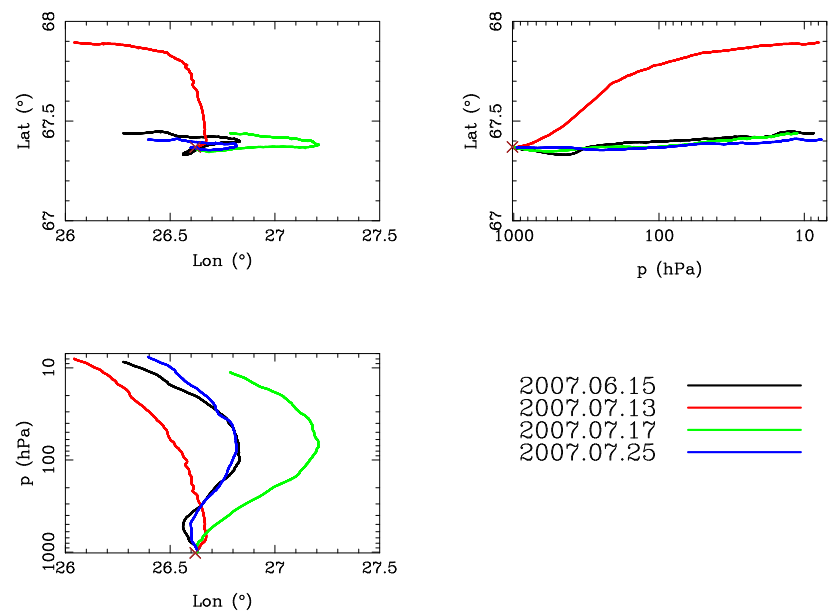

2007.06 .15
2007.07 .13
2007.07 .17

2007.07 .25

Fig. 2. Ascending trajectories of the four $\mathrm{CFH}$ sondes selected for comparison as shown in Table 1. The big brown cross is the launch location at the FMI Artic Research Centre observatory in Sodankylä.

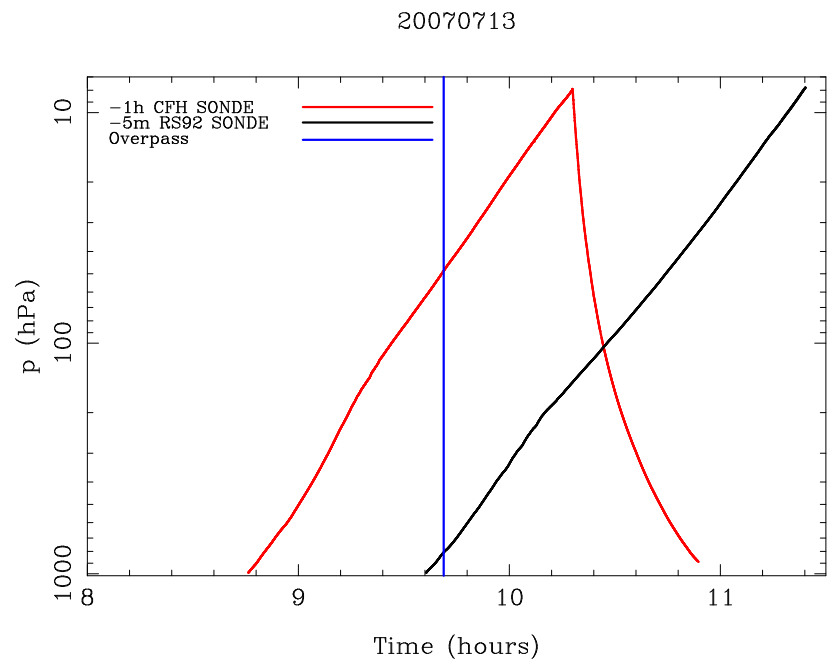

Fig. 3. Vertical position of the sonde versus time. The sonde, which carries an RS92 and a CFH, launched $1 \mathrm{~h}$ before overpass time is plotted (red) together with the sonde, carrying only an RS92, launched $5 \mathrm{~min}$ before overpass time (black). The overpass time is plotted as a vertical line (blue).

- Moisture from RS92 profiles are not usable above the tropopause level, usually between 200 to $300 \mathrm{hPa}$. Whenever we calculate radiances for this type of profile, we substitute the moisture above this level with the $\mathrm{CFH}$ sonde measurements.

- Moisture measured with the CFH sonde does not seem to measure properly above approximately $40 \mathrm{hPa}$. Whenever we calculate radiances for this type of profile, we substitute the moisture above this level with the ECMWF analyses. 
20070713

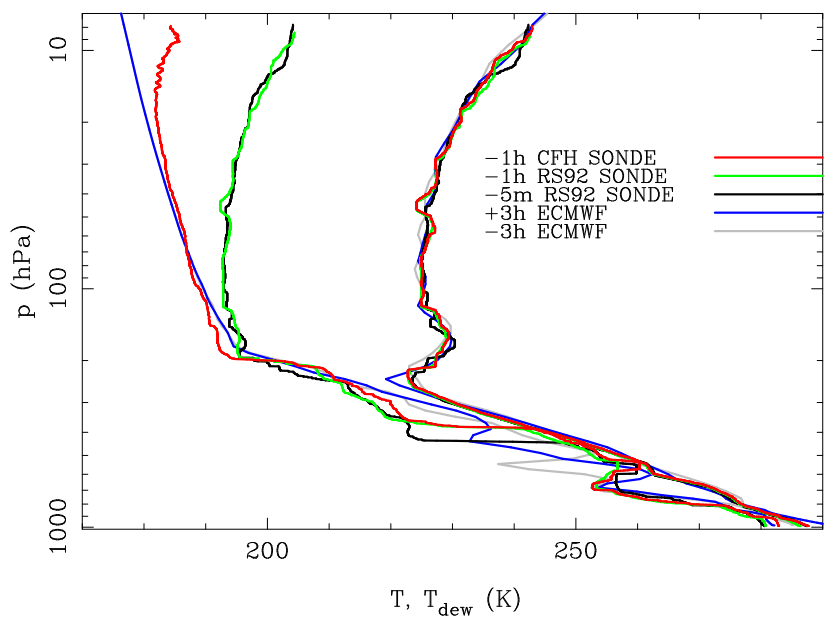

Fig. 4. Temperature (right) and water vapour profiles (left) for the CFH and RS92 sonde launched $1 \mathrm{~h}$ before overpass time (red and green, respectively), the RS92 sonde launched $5 \mathrm{~min}$ before IASI overpass (black) and the ECMWF analysis profile approximately $3 \mathrm{~h}$ before and after satellite overpass (grey and blue, respectively). Note the big moisture variation between the $1 \mathrm{~h}$ and $5 \mathrm{~min}$ before overpass launch measurements at the $400 \mathrm{hPa}-\mathrm{level}$.

- Moisture profiles can vary substantially between sondes launched $1 \mathrm{~h}$ and $5 \mathrm{~min}$ before overpass. We can see this in Fig. 4 at the $400 \mathrm{hPa}$ level.

- Upper troposphere, lower stratosphere moisture from ECMWF analyses can be substantially different to the ones measured with the CFH or RS92 sonde (see Fig. 5 at $200 \mathrm{hPa}$ ).

\subsection{Sonde corrections}

Observed radiances measured with IASI should be compared with calculated radiances using the best known atmospheric state vectors available and the LBLRTM (11.3 and 11.6) or OSS RTMs. CFH sondes are always taken as a reference, assuming that they measure perfectly in all conditions and no corrections are applied to them (except above $40 \mathrm{hPa}$, where we insert ECMWF analyses, as we have seen). On the other hand, RS92s show a large dry bias in the humidity measurements when measuring during daytime, which we have to correct for. This dry bias is believed to be caused by solar radiation impinging on the detectors (Vömel et al., 2007b). It is important to note that because of this, it is difficult to model and precisely correct individually each radiosonde measurement. Three different types of humidity corrections have been applied to the RS92s in this paper:

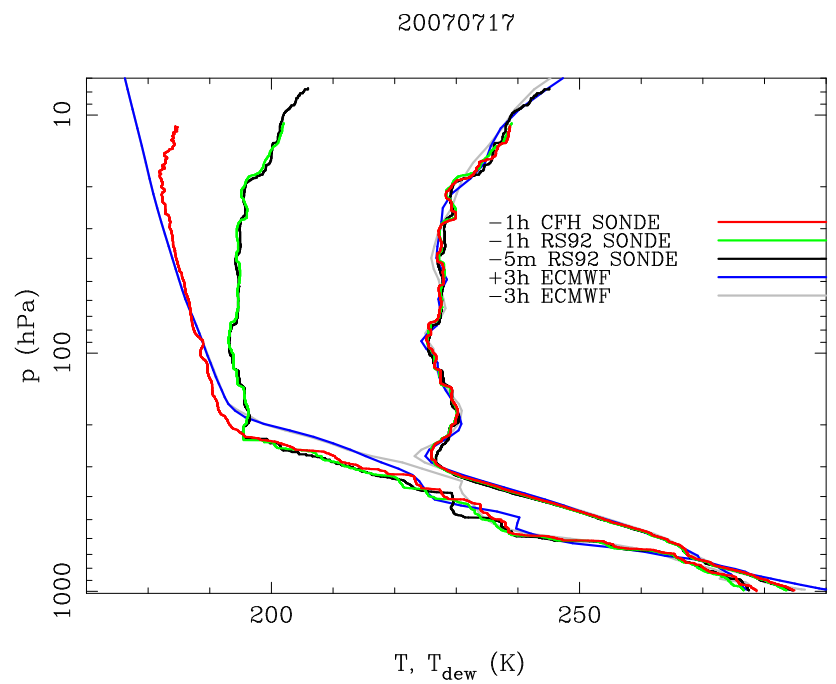

Fig. 5. Temperature (right) and water vapour profiles (left) for the CFH and RS92 sonde launched $1 \mathrm{~h}$ before overpass time (red and green, respectively), the RS92 sonde launched $5 \mathrm{~min}$ before IASI overpass (black) and the ECMWF analysis profile approximately $3 \mathrm{~h}$ before and after satellite overpass (grey and blue, respectively). Note the big difference between the ECMWF analyses and the radiosondes moisture at $200 \mathrm{hPa}$.

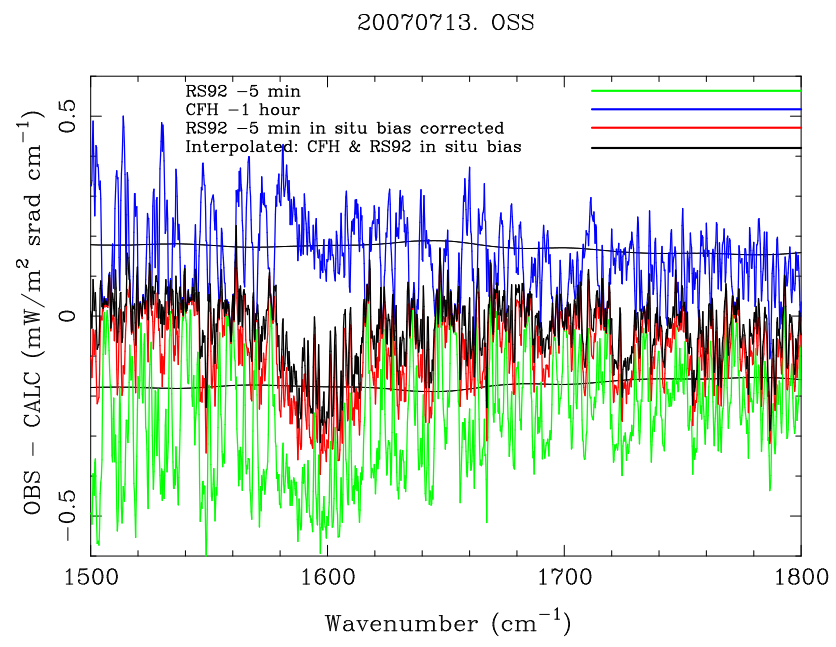

Fig. 6. Residual radiances, IASI observed minus calculated with OSS RTM, for different atmospheric profiles: CFH sonde launched $1 \mathrm{~h}$ before overpass (blue), RS92 sonde launched $5 \mathrm{~min}$ before overpass (green), same sonde but with the "in situ" bias correction (red) and the time interpolated profile (black) using CFH (launched $1 \mathrm{~h}$ before overpass) and "in situ" bias corrected RS92 (launched 5 min before overpass) measurements. Thin black nearly flat lines correspond to three sigma IASI instrument noise. 
20070713. OSS

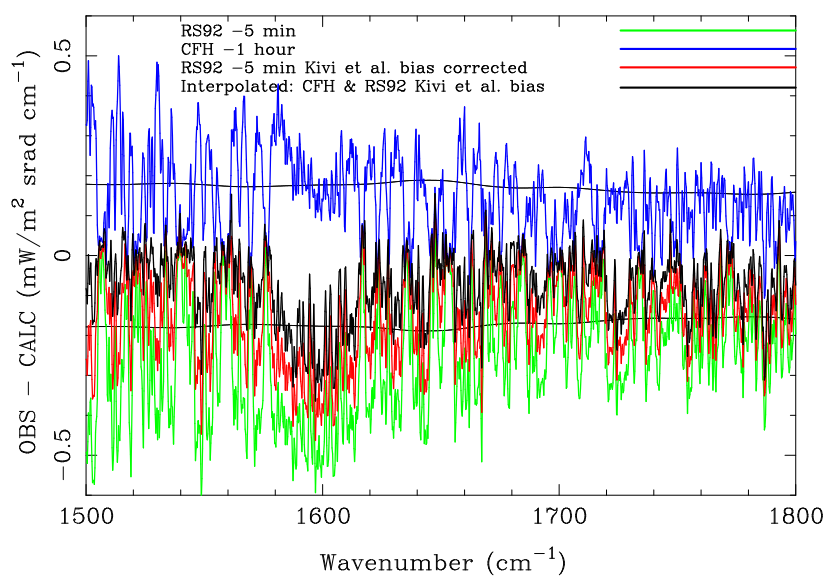

Fig. 7. Residual radiances, IASI observed minus calculated with OSS RTM, for different atmospheric profiles: $\mathrm{CFH}$ sonde launched $1 \mathrm{~h}$ before overpass (blue), RS92 sonde launched 5 min before overpass (green), same sonde but with the Kivi et al. bias correction (red) and the time interpolated profile (black) using CFH (launched $1 \mathrm{~h}$ before overpass) and Kivi et al. bias corrected RS92 (launched 5 min before overpass) measurements. Thin black nearly flat lines correspond to three sigma IASI instrument noise.

- What we will call "in situ" bias correction, which consists of calibrating each day independently by calculating the dew point temperature difference as a function of pressure between the CFH sonde and the RS92 measurement flown on the same balloon, which were launched $1 \mathrm{~h}$ before IASI overpass time. This bias correction is then applied to restore the RS92 sonde measurement launched $5 \mathrm{~min}$ before satellite overpass time. Since the radiation conditions within $1 \mathrm{~h}$ between both radiosonde observations during the Sodankylä summer morning should not change much, this method should preserve the fine detail of the dry bias as the balloon ascends in the atmosphere and its incident radiation conditions change.

- In general, a correction, which depends on pressure, is available that works statistically on average (Vömel et al., 2007b). As we have seen (Eqs. 1 and 2), in this paper we will use a slightly modified version of this bias correction targeted specifically to the modified RS92 radiosondes used here (Kivi et al., 2009). These bias corrections should be re-calculated (Kivi et al., 2009) every time a new modification of RS92 sondes is used. We will denominate this as "Kivi et al." bias correction. It is important to note that the coefficients for this bias correction (Eq. 1) have been obtained from the comparison of CFH and RS92 sondes flying with the same balloons launched $1 \mathrm{~h}$ before satellite overpass time combining all days together, but have been applied to the RS92s sondes launched $5 \mathrm{~min}$ before IASI overpass time of those very same days. In other words, although the corrections are a statistical combination of measurements from several different days, they are applied to those same days which most probably have very similar solar radiation conditions. It remains to be proven whether this kind of corrections can be applied between two completely different sets of measurements or solar radiation conditions.

- For illustration purposes, and because it fits better with the OSS model, we will use a third bias correction which is the "Kivi et al." one corrected with a $2 \%$ additional relative humidity, which we will denote as "Kivi et al. +2",

$$
\mathrm{RH}_{\text {corr }}=\mathrm{RH} / C_{\mathrm{rad}}+2 .
$$

\subsection{Comparisons}

We have plotted the observed minus calculated radiance differences after each one of the corrections proposed above are applied to the data. To begin with, we plot the observed minus calculated radiances obtained with the raw radiosonde data and the OSS RTM for a particular sample day in Fig. 6. In blue we plot the difference for the $\mathrm{CFH}$ sonde which was launched $1 \mathrm{~h}$ before IASI overpass time. In green is the difference for the RS92 sonde launched 5 min before satellite overpass. For referene purposes, thin, black, nearly flat lines corresponding to three sigma IASI instrument noise are also plotted. To be more precise, they are three times the square root of the diagonal of the IASI covariance matrix instrument noise provided by CNES (explained in detail in Pequignot et al., 2008). As we can see, the calculated radiances are significantly off the plus minus three sigma IASI instrument noise band.

We now correct the RS92 sonde measurements with the three different dry bias corrections. The observed minus calculated radiances using the "in situ" moisture correction are shown in Fig. 6 as a red line. In Fig. 7 the observed minus calculated radiances using the Kivi et al. moisture correction are shown in Fig. 7 again as a red line. Finally, in Fig. 8 the difference using the "Kivi et al. +2 " bias correction is shown also in red. We see the big improvement the RS92 measurements have undergone for all bias corrections, lying now within the plus minus three sigma IASI instrument noise band.

The next step is to co-locate in space and time the IASI measurement with the radiosonde observations, which will always inevitably never coincide with the satellite overpass.

Regarding spatial co-location, only the closest IASI field of view to the Sodankylä observatory was selected for comparison purposes, which has a footprint that usually encloses the observatory location. The radiosonde locations are plotted in Fig. 2. This figure shows that the radiosondes do not 
20070713. OSS

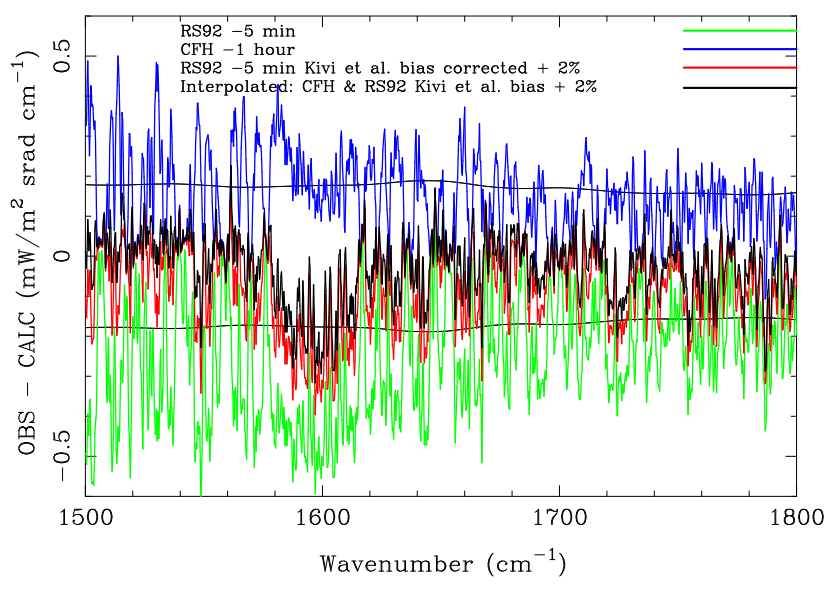

Fig. 8. Residual radiances, IASI observed minus calculated with OSS RTM, for different atmospheric profiles: CFH sonde launched $1 \mathrm{~h}$ before overpass (blue), RS92 sonde launched 5 min before overpass (green), same sonde but with the "Kivi et al. +2" bias correction (red) and the time interpolated profile (black) using $\mathrm{CFH}$ (launched $1 \mathrm{~h}$ before overpass) and Kivi et al. +2 bias corrected RS92 (launched 5 min before overpass) measurements. Thin black nearly flat lines correspond to three sigma IASI instrument noise.

drift very far away from the launch location. For this reason, together with the fact that we are studying IASI channels which have contributions of temperature and moisture from the mid-troposphere to the low stratosphere, which usually show small spatial variability, we have not attempted any spatial co-location corrections. We are, thus, effectively assuming that all radiosondes are perfectly spatially co-located with the IASI fields of view. The validity of this assumption will rely on the results obtained. Further work would be needed to explore this assumption.

Time co-location is achieved by combining the CFH sondes launched $1 \mathrm{~h}$ before overpass time and the bias corrected humidity ones (RS92) launched $5 \mathrm{~min}$ before satellite overpass. A linear interpolation or extrapolation to the overpass time per altitude level (see Fig. 3) is done with these sonde temperature and moisture profiles in a similar fashion to Tobin et al. (2006). Results of the observed minus calculated radiances for the interpolated profiles are shown as a black line in Figs. 6-8 with the three different bias corrections. With these final interpolated profiles the radiance comparisons improve significantly and are fitted within three sigma IASI instrument noise band. Note that for the one example plotted in this paper (Figs. 6-8), the time interpolation appears to be not very critical. This is not the case for some of the other radiosonde measurements, for which, for brevity reasons, we are not showing equivalent figures here. In order to match all radiances from all four radiosondes, it is necessary to perform the time interpolation.
Chans. $1500<\nu<1570$ or $1615<\nu<1800 \mathrm{~cm}^{-1}$. All days

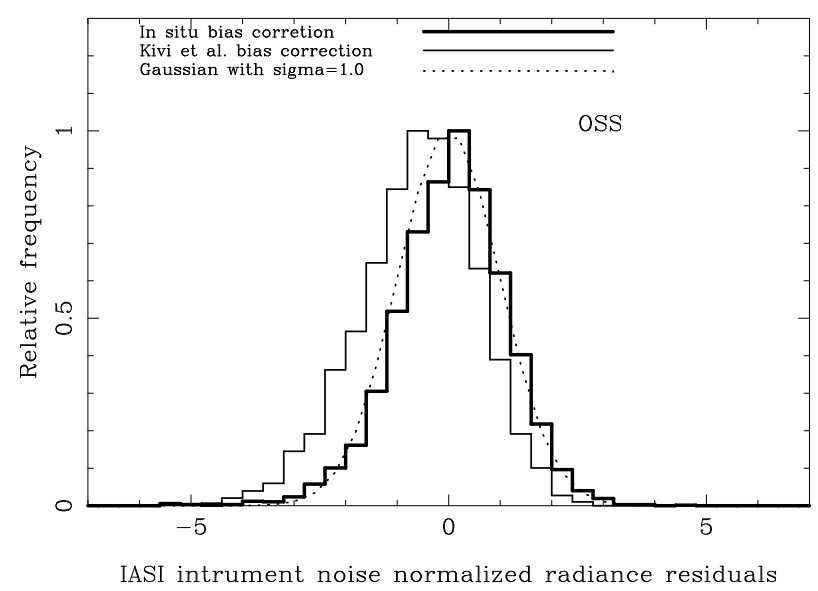

Fig. 9. Histogram of the residual radiances, IASI observed minus calculated with OSS RTM and time interpolated profiles, for all clear days (4) in the spectral range, $1500 \mathrm{~cm}^{-1} \leq v \leq 1570 \mathrm{~cm}^{-1}$ and $1615 \mathrm{~cm}^{-1} \leq v \leq 1800 \mathrm{~cm}^{-1}$. One set of interpolated profiles have been derived from the CFH sonde launched $1 \mathrm{~h}$ before IASI overpass and the "in situ" bias corrected RS92 sonde launched 5 min before satellite overpass (thick solid line). The other set of interpolated profiles have been derived from the $\mathrm{CFH}$ sonde launched $1 \mathrm{~h}$ before IASI overpass and the Kivi et al. bias corrected RS92 sonde launched $5 \mathrm{~min}$ before satellite overpass (thin solid line). For reference, a Gaussian curve with a $\sigma$ of 1.0 is shown (dotted line).

We can now summarize the results of all these measurements by normalizing the radiance residuals with the one sigma IASI instrument noise and plotting a histogram of them. For this, we select highly absorptive water vapour wavenumbers, $v, 1500 \mathrm{~cm}^{-1} \leq v \leq 1570 \mathrm{~cm}^{-1}$ and $1615 \mathrm{~cm}^{-1} \leq v \leq 1800 \mathrm{~cm}^{-1}$. Since these wavenumbers have their peak absorption in the stratosphere or upper troposphere, they are not affected by low level clouds. The results generated by interpolating the temperature and water vapour sondes with the "in situ" and the Kivi et al. bias corrections for the three different RTMs OSS, LBLRTM 11.3 and LBLRTM 11.6 are shown in Figs. 9-11, respectively. A one sigma Gaussian curve is plotted on top of the histograms as a dotted line for comparison purposes. We can see that all models fit very well with a one sigma Gaussian. The only difference is the slight displacement of one histogram with respect to the others, in other words, a small bias. OSS seems to fit better with the "in situ" bias correction, while LBLRTM 11.6 seems to fit better with the Kivi et al. bias correction. To understand the origin of this slight displacement or bias of these curves we have plotted Fig. 12. It shows the "in situ" and the Kivi et al. +2 dry bias corrections together with the OSS RTM. In this case, all three histograms overlap. This shows that the difference between all the plotted histograms is a mere $2 \%$ bias correction in the absolute relative humidity. Which means IASI is sensitive enough 
Chans. $1500<\nu<1570$ or $1615<\nu<1800 \mathrm{~cm}^{-1}$. All days

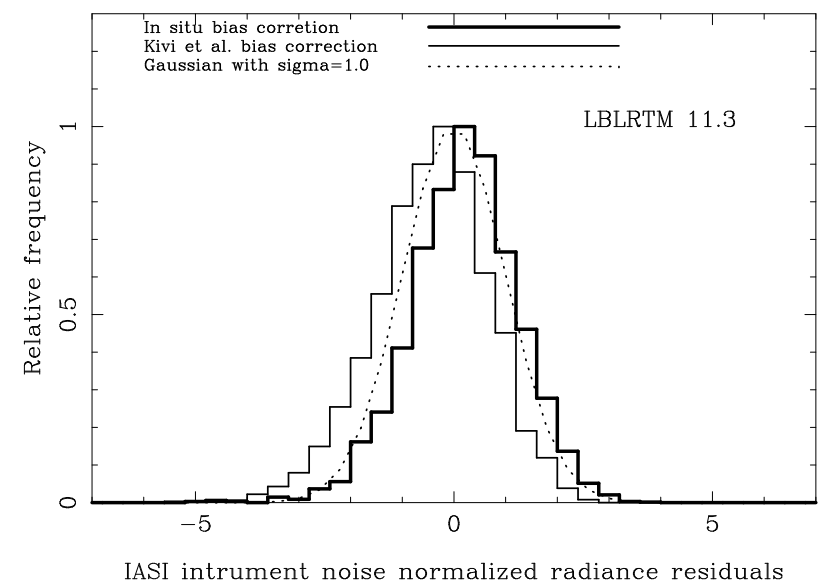

Fig. 10. Histogram of the residual radiances, IASI observed minus calculated with LBLRTM 11.3 RTM and time interpolated profiles, for all clear days (4) in the spectral range, $1500 \mathrm{~cm}^{-1} \leq v \leq$ $1570 \mathrm{~cm}^{-1}$ and $1615 \mathrm{~cm}^{-1} \leq v \leq 1800 \mathrm{~cm}^{-1}$. One set of interpolated profiles have been derived from the $\mathrm{CFH}$ sonde launched $1 \mathrm{~h}$ before IASI overpass and the "in situ" bias corrected RS92 sonde launched $5 \mathrm{~min}$ before satellite overpass (thick solid line). The other set of interpolated profiles have been derived from the CFH sonde launched $1 \mathrm{~h}$ before IASI overpass and the Kivi et al. bias corrected RS92 sonde launched 5 min before satellite overpass (thin solid line). For reference, a Gaussian curve with a $\sigma$ of 1.0 is shown (dotted line).

to see the presence of this small bias difference throughout the whole atmospheric profile. Clearly, the instrumentation available, as well as the knowledge in the RTMs does not allow us to infer which of the positions of the Gaussian shaped histograms, or biases, is the correct one.

In Fig. 13 we plot the histograms separately for each of the four observation days. We can verify how the histograms of all four days fit well to a one sigma Gaussian distribution.

\section{Retrieval bias corrections and measurement error covariance matrix}

The bias corrections and the measurement error covariance matrix which would optimize our retrievals (Calbet and Schlüssel, 2006) would be the mean and standard deviation (ideally, it should be the full covariance matrix) of the observed minus calculated radiances shown above. Unfortunately, we only have four cases from which it is difficult to draw a representative statistics. Nevertheless, for illustration purposes, we plot the mean and standard deviation of such differences in Fig. 14 and 15 for OSS and LBLRTM 11.6 respectively with "in situ" bias correction. We can see how the bias is mostly contained within the one sigma IASI instrument noise and the standard deviation fluctuates around this value, but there are some particular wavenumbers which seem to deviate from this behavior.
Chans. $1500<\nu<1570$ or $1615<\nu<1800 \mathrm{~cm}^{-1}$. All days

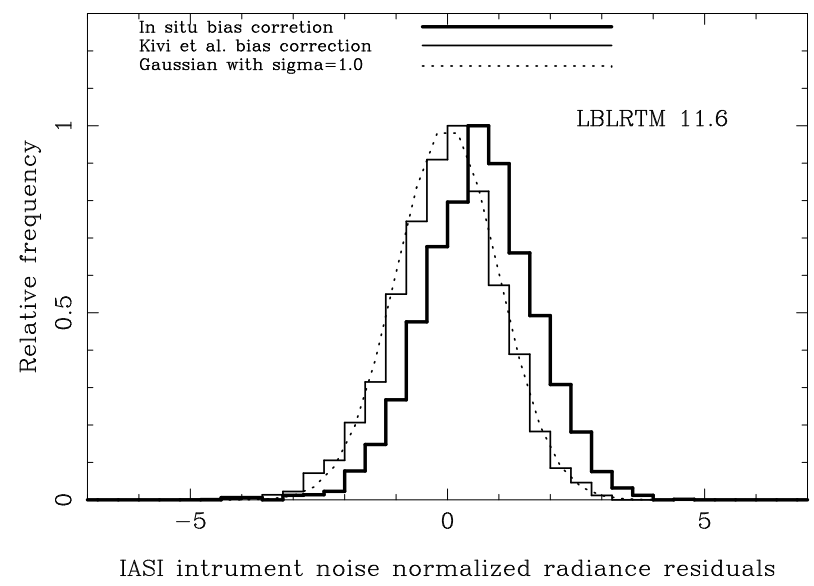

Fig. 11. Histogram of the residual radiances, IASI observed minus calculated with LBLRTM 11.6 RTM and time interpolated profiles, for all clear days (4) in the spectral range, $1500 \mathrm{~cm}^{-1} \leq v \leq$ $1570 \mathrm{~cm}^{-1}$ and $1615 \mathrm{~cm}^{-1} \leq v \leq 1800 \mathrm{~cm}^{-1}$. One set of interpolated profile have been derived from the $\mathrm{CFH}$ sonde launched $1 \mathrm{~h}$ before IASI overpass and the "in situ" bias corrected RS92 sonde launched $5 \mathrm{~min}$ before satellite overpass (thick solid line). The other set of interpolated profiles have been derived from the CFH sonde launched $1 \mathrm{~h}$ before IASI overpass and the Kivi et al. bias corrected RS92 sonde launched $5 \mathrm{~min}$ before satellite overpass (thin solid line). For reference, a Gaussian curve with a $\sigma$ of 1.0 is shown (dotted line).

\section{Conclusions}

We have proven that, with adequate radiosonde measurements and RTMs, it is possible to reproduce IASI measurements to within the accuracy of one sigma instrument noise. The measurement methodology that has been proven useful is based on launching a CFH and an RS92 sondes $1 \mathrm{~h}$ and an RS92 sonde 5 min before satellite overpass time.

To reproduce these results, we need sonde measurements with an extremely low bias $<0.2 \%$ in absolute terms and high accuracy of relative humidity, especially in the upper troposphere and low stratosphere, where RS92 and ECMWF analyses are not reliable. The only sonde instruments that can get close to these numbers seem to be the $\mathrm{CFH}$ sondes.

We have seen that IASI radiances are sensitive to a very low bias difference of only $2 \%$ in absolute relative humidity. Although IASI is not sensitive enough to detect such small differences in one single layer, it is sensitive enough to detect this small bias applied to the whole humidity profile. Because this range of humidities is within the limits of the measuring devices used in this paper and also within the accuracies of the present RTMs, we can only say that the RTMs are in agreement with the observations, from the bias point of view, to within about $2 \%(\Delta \mathrm{RH})$. 
Chans. $1500<\nu<1570$ or $1615<\nu<1800 \mathrm{~cm}^{-1}$. All days

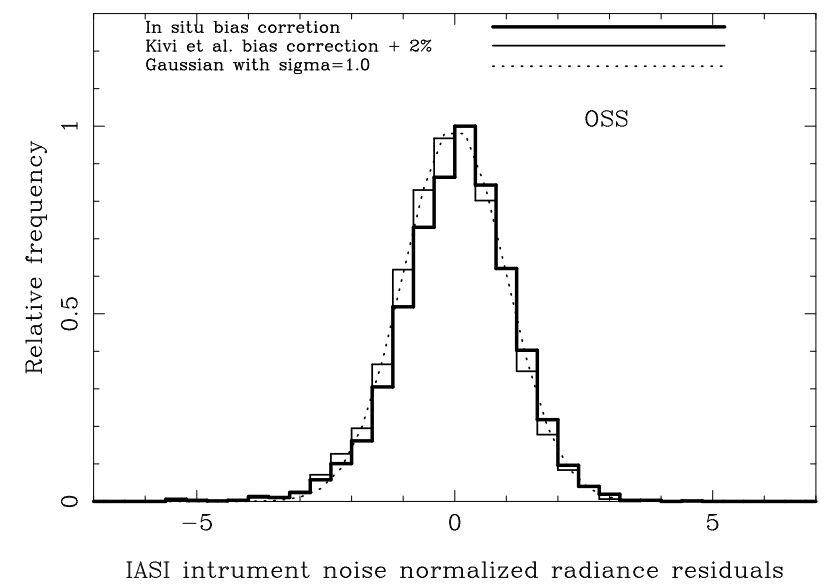

Fig. 12. Histogram of the residual radiances, IASI observed minus calculated with OSS RTM and time interpolated profiles, for all clear days (4) in the spectral range, $1500 \mathrm{~cm}^{-1} \leq v \leq 1570 \mathrm{~cm}^{-1}$ and $1615 \mathrm{~cm}^{-1} \leq v \leq 1800 \mathrm{~cm}^{-1}$. One set of interpolated profiles have been derived from the CFH sonde launched $1 \mathrm{~h}$ before IASI overpass and the "in situ" bias corrected RS92 sonde launched 5 min before satellite overpass (thick solid line). The other set of interpolated profiles have been derived from the $\mathrm{CFH}$ sonde launched $1 \mathrm{~h}$ before IASI overpass and the Kivi et al. $+2 \%$ bias corrected RS92 sonde launched $5 \mathrm{~min}$ before satellite overpass (thin solid line). For reference, a Gaussian curve with a $\sigma$ of 1.0 is shown (dotted line).

Base on the experience gathered in this study, spatial colocation does not seem to play a big role in the radiance matching, but temporal co-location and time interpolation are critical to achieve these results.

The question that immediately arises is whether we can achieve these same results using RS92 sondes only, which would be beneficial because of the savings involved. The answer is not clear. It would appear to have a positive answer because we are also achieving good results with a statistical correction Kivi et al. (2009). But we have to remember that this correction has been calculated with the comparison of CFH and RS92 sondes from this same campaign, resulting in a slightly incestuous process. The radiance match would clearly not work using the more standard Vömel et al. (2007b) RS92 corrections, recalling that the RS92 humidity sensors used here are significantly different from the ones in Vömel et al. (2007b). A humidity bias correction calculated and applied at the same day in similar observing conditions (what we have called "in situ" correction) seems to be the more physical way to proceed, but at the cost of having to launch a CFH sonde. To summarize, it is difficult to asses whether these same results could be achieved with RS92 sondes only, but the fact that we had to use bias corrections calculated in similar observing conditions as the measurements which needed to be corrected seems to imply that CFH or equivalent quality measurements are necessary. On the other
Chans. $1500<\nu<1570$ or $1615<\nu<1800 \mathrm{~cm}^{-1}$. All days

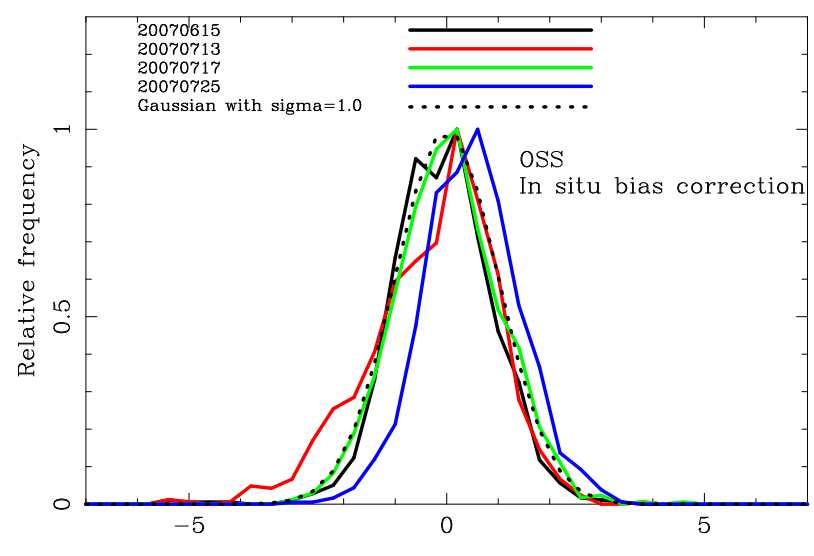

IASI intrument noise normalized radiance residuals

Fig. 13. Histogram of the residual radiances, IASI observed minus calculated with OSS RTM and the time interpolated profiles, for all clear days (4) in the spectral range, $1500 \mathrm{~cm}^{-1} \leq v \leq 1570 \mathrm{~cm}^{-1}$ and $1615 \mathrm{~cm}^{-1} \leq \nu \leq 1800 \mathrm{~cm}^{-1}$. The interpolated profile has been derived from the CFH sonde launched $1 \mathrm{~h}$ before IASI overpass and the "in situ" bias corrected RS92 sonde launched 5 min before satellite overpass. The results for each one of the different observing days are shown independently in this figure. A one sigma Gaussian is shown as a dotted line.

hand, from the comparisons of RS92s, CFHs and ECWMF analysis we know that the only method that will give a reliable measurement of humidity in the upper troposphere/low stratosphere are the CFHs (see Fig. 5 and Sect. 5.2).

If we want to have significant statistics to derive proper bias corrections and measurement error covariance matrices for retrieval purposes and possibly further advance the RTMs with these kind of data comparisons we will need far more data than the one provided from this campaign. It would be advisable, if possible, to extend these kind of measurements by taking advantage of the current or planned networks of high accuracy atmospheric state characterization (GRUAN, 2010) by co-location in time these measurements with hyperspectral sensor overpasses. This would increase the matches by a significant amount at an affordable cost due to the synergy. On the other hand, it is expected to have in the future hyperspectral infrared sounders in geostationary orbit providing measurements in roughly $1 \mathrm{~h}$ time intervals which should be simple enough to co-locate with existing high measurement accuracy networks.

Acknowledgements. Almost all figures and calculations in this document have been made using the free software numerical analysis package called PDL (http://pdl.perl.org).

Edited by: S. Buehler 

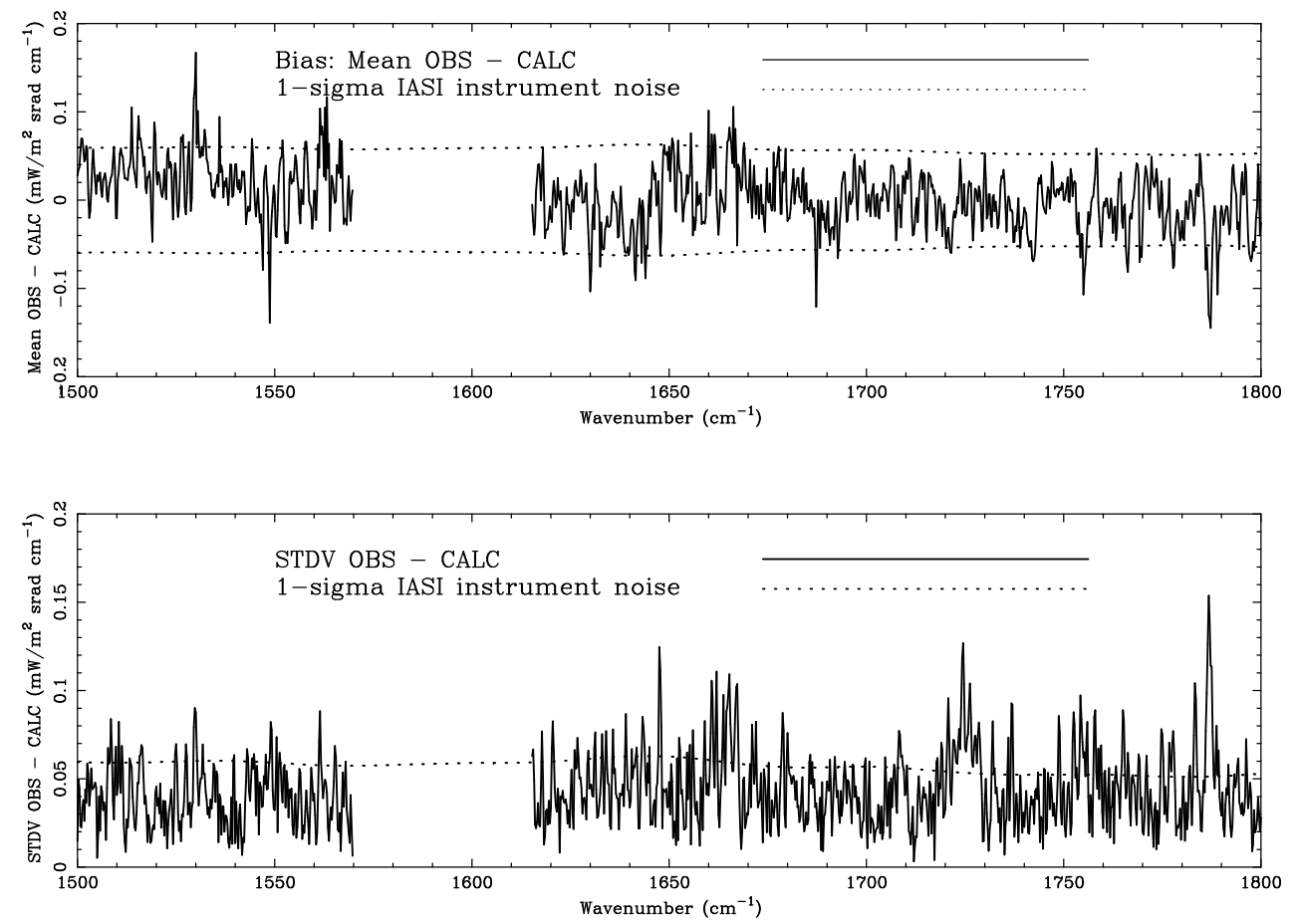

Fig. 14. Bias and standard deviation of IASI observed minus calculated radiances. The calculated radiances have been obtained using OSS and the "in situ" bias correction.
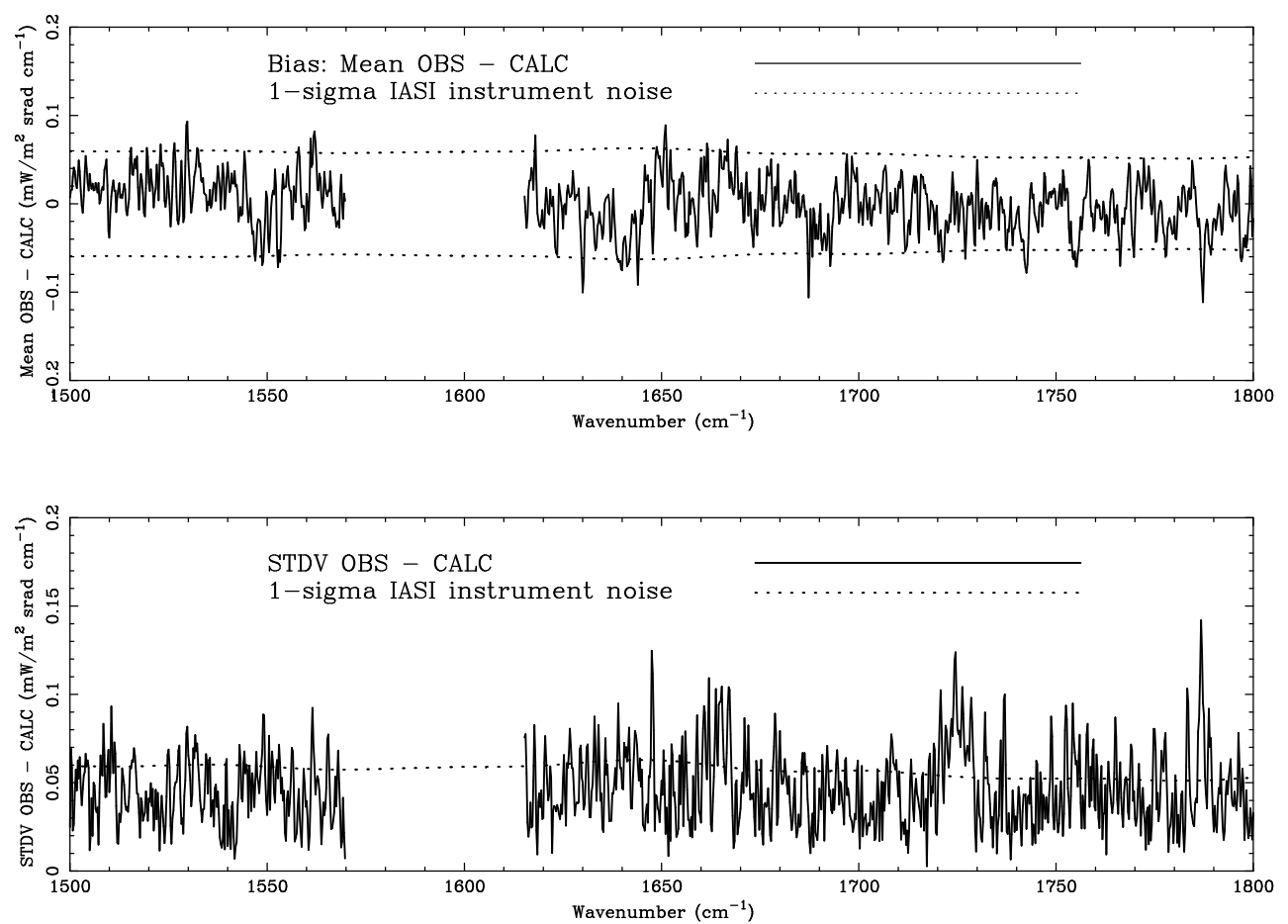

Fig. 15. Bias and standard deviation of IASI observed minus calculated radiances. The calculated radiances have been obtained using LBLRTM 11.6 and the "in situ" bias correction. 


\section{References}

Blackwell, W. J.: A neural-network technique for the retrieval of atmospheric temperature and moisture profiles from high spectral resolution sounding data, IEEE T. Geosci. Remote, 43, 25352546, 2005.

Blumstein, D., Chalon, G., Carlier, T., Buil, C., Hébert, P., Maciaszek, T., Ponce, G., Phulpin, T., Tournier, B., and Siméoni, D.: IASI instrument technical overview and measured performances, SPIE Conference, Denver (Co), SPIE 2004-5543-22, August 2004.

Calbet, X. and Schlüssel, P.: Technical note: analytical estimation of the optimal parameters for the EOF retrievals of the IASI Level 2 Product Processing Facility and its application using AIRS and ECMWF data, Atmos. Chem. Phys., 6, 831-846, doi:10.5194/acp-6-831-2006, 2006.

Chalon, G., Cayla, F., and Diebel, D.: IASI: An Advanced Sounder for Operational Meteorology, Proceedings of the 52nd Congress of IAF, Toulouse France, 1-5 Oct., 2001.

Clough, S. A., Shephard, M. W., Mlawer, E. J., Delamere, J. S., Iacono, M. J., Cady-Pereira, K., Boukabara, S., and Brown, R. D.: Atmospheric radiative transfer modeling: a summary of the AER codes., J. Quant. Spectrosc. Ra., 91, 233-244, 2005.

Coudert, L. H., Wagner, G., Birk, M., Baranov, Yu. I., Lafferty, W. J., and Flaud, J.-M.: The $\mathrm{H}_{2}^{16} \mathrm{O}$ molecule: Line position and line intensity analyses up to the second triad, Journal of Molecular Spectroscopy, 251(1-2), 339-357, 2008.

GRUAN: Weather and Climate - Deutsche Wetterdienst - Startseite GRUAN, http://www.dwd.de/gruan, last access: 18 October, 2010.

Huang, H. and Antonelli, P.: Application of principal component analysis to high-resolution infrared measurement compression and retrieval, J. Appl. Meteorol., 40, 365-388, 2001.

Kivi, R., Kujanpää, J., Aulamo, O., Heikkinen, P., Hassinen, S., Calbet, X., Montagner, F., and Vömel, H.: Observations of water vapor profiles over Northern Finland by satellite and balloon borne instruments, in: Proceedings: 2009 EUMETSAT Meteorological Satellite Conference, 21-25 September 2009, Bath, UK, EUMETSAT P.55, 2009.

Mastenbrook, H. J. and Dinger, J. E.: The measurement of water vapor distribution in the stratosphere, Tech. Rep. NRL 5551, 35 pp., Nav. Res. Lab., Washington DC, 1960.

Miloshevich L. M., Vömel, H., Whiteman, D. N., Lesht, B. M., Schmidlin, F. J., and Russo, F.: Absolute accuracy of water vapor measurements from six operational radiosonde types launched during AWEX-G and implications for AIRS validation, J. Geophys. Res., 111, D09S10, doi:10.1029/2005JD006083, 2006.

Miloshevich, L. M., Vömel, H., Whiteman, D. N., and Leblanc, T.: Accuracy assessment and correction of Vaisala RS92 radiosonde water vapor measurements, J. Geophys. Res., 114, D11305, doi:10.1029/2008JD011565, 2009.

Nash, J., Smout, R., and Oakley, T.: WMO Intercomparison of High Quality Radiosonde Systems, Vacoas, Mauritius, 2-25 February 2005, Instruments and observing methods report No. 83, WMO, Geneva, Switzerland, 2006.

Niro, F., Jucks, K., and Hartmann, J.-M.: Spectra calculations in central and wing regions of CO2 IR bands. IV: Software and database for the computation of atmospheric spectra, J Quant Spectrosc Radiat Transfer, Vol. 95, 469-481, 2005.

Moncet, J., Uymin, G., Lipton, A. E., and Snell, H. E.: Infrared radiance modeling by optimal spectral sampling, J. Atmos. Sci., 65, 3917-3934, 2008.

Oltmans, S. J. and Hofmann, D. J.: Increase in lower-stratospheric water vapour at a midlatitude Northern Hemisphere site from 1981 to 1994, Nature, 374, 146-149, 1995.

Paukkunen, A., Antikainen, V., and Jauhiainen, H.: Accuracy and performance of the new Vaisala RS90 radiosonde in operational use, paper presented at 11th Symposium on Meteorological Observations and Instrumentation, Am. Meteorol. Soc., Albuquerque, N. M., 14-18, Jan, 2001.

Pequignot, E., Blumstein D., and Larigauderie, C.: CNES Technical Note: IASI Noise Covariance Matrix, IA-TN-0000-3271-CNE, 2008.

Pougatchev, N., August, T., Calbet, X., Hultberg, T., Oduleye, O., Schlssel, P., Stiller, B., Germain, K. St., and Bingham, G.: IASI temperature and water vapor retrievals - error assessment and validation, Atmos. Chem. Phys., 9, 6453-6458, doi:10.5194/acp9-6453-2009, 2009.

Rodgers, C. D.: Inverse methods for atmospheric sounding. Theory and practice, World Scientific, Singapore, 2000.

Smith, W. L. Sr., Harrison, F., Hinton, D., Miller, J., Bythe, M., Zhou, D., Revercomb, H., Best, F., Huang, H., Knuteson, R., Tobin, D., Velden, C. S., Bingham, G., Huppi, R., Thurgood, A., Zollinger, L., Epslin, R., and Petersen, R.: The Geosynchronous Imaging Fourier Transform Spectrometer (GIFTS) (Invited Presentation), The 11th Conference on Satellite Meteorology and Oceanography (Madison, WI), 2001.

Strow, L. L., Hannon, S. E., De-Souza Machado, S., Motteler, H. E., and Tobin, D. C.: Validation of the Atmospheric Infrared Sounder radiative transfer algorithm, J. Geophys. Res., 111, D09S06, doi:10.1029/2005JD006146, 2006.

Suortti, T. M., Kats, A., Kivi, R., Kämpfer, N., Leiterer, U., Miloshevich, L. M., Neuber, R., Paukkunen, A., Ruppert, P., Vömel, H., and Yushkov, V.: Tropospheric comparisons of Vaisala radiosondes and balloon-borne frost-point and Lyman$\alpha$ hygrometers during the LAUTLOS-WAVVAP experiment, J. Atmos. Ocean. Tech., 25, 149-166, 2008.

Tjemkes, S. A., Patterson, T., Rizzi, R., Shephard, M. W., Clough, S. A., Matricardi, M., Haigh, J. D., Hopfner, M., Payan, S., Trotsenko, A., Scott, N., Rayer, P., Taylor, J. P., Clerbaux, C., Strow, L. L., DeSouza-Machado, S., Tobin, D., and Knuteson, R.: The ISSWG line-by-line inter-comparison experiment, J. Quant. Spectrosc. Ra., 77, 433-453, 2003.

Tobin, D. C., Revercomb, H. E., Knuteson, R. O., Lesht, B. M., Strow, L. L., Hannon, S. E., Feltz, W. F., Moy, L. A., Fetzer, E. J., and Cress, T. S.: Atmospheric radiation measurement site atmospheric state best estimates for atmospheric infrared sounder temperature and water vapor retrieval validation, J. Geophys. Res., 111, D09S14, doi:10.1029/2005JD006103, 2006.

Vaisala, Data continuity (available at http://www.vaisala.com/ weather/products/datacontinuity.html), 2010.

Vömel, H., David, D. E., and Smith, K.: Accuracy of tropospheric and stratospheric water vapor measurements by the cryogenic frost point hygrometer: Instrumental details and observations, J. Geophys. Res., 112, D08305, doi:10.1029/2006JD007224, 2007a.

Vömel, H., Selkirk, H., Miloshevich, L., Valverde-Canossa, J., Valds, J., Kyrö, E., Kivi, R., Stolz, W., Peng, G., and Diaz, J. A.: Radiation dry bias of the Vaisala RS92 humidity sensor, J. At- 
mos. Ocean. Tech., 24, 953-963, $2007 \mathrm{~b}$.

Vömel, H., Yushkov, V., Khaykin, S., Korshunov, L., Kyrö, E., and Kivi, R.: Intercomparisons of stratospheric water vapor sensors: FLASH-B and NOAA/CMDL frost-point hygrometer, J. Atmos. Ocean. Tech., 24, 941-952, 2007c.
Zhou, D. K., Smith, W. L., Li, J., Howell, H. B., Cantwell, G. W., Larar, A. M., Knuteson, R. O., Tobin, D. C., Revercomb, H. E., and Mango, S. A.: Thermodynamic product retrieval methodology and validation for NAST-I, Appl. Optics, 4, 6957-6967, 2002. 